\title{
Tradisi Malakok dan Implikasinya terhadap Kehidupan Sosial Masyarakat Tambun Ijuak Kecamatan Payakumbuh Kabupaten 50 Kota
}

Zahratul Atikah, Nurman, Isnarmi

Program Studi Pendidikan Pancasila dan Kewarganegaraan

Universitas Negeri Padang

E-mail:

\section{ABSTRAK}

Penelitian ini dilatarbelakangi oleh kondisi Tambun Ijuak yang merupakan salah satu daerah yang beda di Kecamatan Payakumbuh karena banyak para pendatang atau kaum yang akan Malakok baik itu secara perorangan ataupun kelompok. Jenis penelitian ini adalah penelitian kualitatif dengan menggunakan metode deskriptif. Lokasi penelitian adalah di Tambun Ijuak Kecamatan Payakumbuh. Teknik pengumpul data yang digunakan adalah wawancara, observasi langsung dan studi documenter. Hasil penelitian adalah sebagai berikut. Pertama, pra prosedur Malakok menjelaskan bahwa adanya beberapa prosedur yang harus dilaksanakan oleh kaum pendatang sebelum melaksanakan prosedur Malakok. Kedua, prosedur tradisi Malakok yaitu adanya syarat yg harus dipenuhi diantaranya $\sim$ carano diisi siriah langkok, beberapa bisa diuangkan ataupun emas,persembahan kerbau atau kambing yang sudah layak dikorbankan untuk upacara pemberian suku, setelah itu adanya syarat lain yang harus dilaksanakan seperti pihak-pihak yang menerima Malakok tersebut persetujuan dari wali nagari setempat,adanya kaum penerima dan kaum pendatang dan panghulu disetiap suku dan setelah melaksanakan prosedur Malakok dapat melaksanakan penandatanganan berkas dan serah terima kepada masyarakat dan keluarga yang di lakokkan. Ketiga, implikasi terhadap masyarakat lokal Tambun Ijuak yaitu adanya struktur sosial yang baru didalam kehidupan sosial masyarakat, bertambahnya jumlah penduduk, terjalinnya komunikasi dan ikatan silaturrahmi yang baru. Sedangkan implikasi Malakok terhadap masyarakat pendatang di Tambun Ijuak yaitu masyarakat pendatang lebih bisa berinteraksi dengan baik dengan masyarakat local. Masyarakat pendatang dapat membangun relasi yang baik dengan masyarakat lokal baik itu dalam bidang pekerjaan dan hal penting lainnya, serta adanya sikap integritas yang baik antara masyarakat pendatang dengan masyarakat lokal.

Kata Kunci: Malakok, tradisi, Payakumbuh

\section{ABSTRACT}

This research was motivated by Tambun Ijuak which is one of the different areas in Payakumbuh District because many migrants or people will be Malakok either by individuals or groups. This type of research is a qualitative research using descriptive methods. The research location is Tambun Ijuak, Payakumbuh District. Data collection techniques used were interviews, direct observation and documentary studies. The results of the study are as 
follows. First, Malakok procedure explains some procedures that must be carried out by migrants before carrying out the Malakok procedure. Then Malakok tradition procedure is a requirement for who has to be agreed to - carano agrees to siriah langkok, some can be cashed in addition to gold, buffalo or goat offerings that have been sacrificed for tribal ceremonies, so this is a necessary necessity as others need to accept Malakok the agreement from the local guardian nagari, the existence of the recipient and the migrants and the panghulu in each tribe and after carrying out the procedure Malakok can carry out the signing of documents and the handover of the people and families in doing. Third, the implications for the local communities are tambun ijuak namely the existence of a new social structure in the social life of the community, establishing new communication and silaturrahmi ties. While the implications of Malakok for migrant communities in Tambun Ijuak, namely migrant communities can be reproduced well with local communities, newcomers can make good relations with local communities both related to activities and other important things, then the existence of good integrity between migrants and the local community.

Keywords : Malakok, tradition, Payakumbuh city

This work is licensed under the Creative Commons Attribution-ShareAlike 4.0 International License. (C2019 by author. 


\section{PENDAHULUAN}

Masyarakat Minangkabau merupakan masyarakat yang sangat egaliter seperti pepatah Minangkabau " dima bumi dipijak di sinan rantiang di patah, di situ aie disauak, disinan langik dijunjuang, dan disitu adaik bapakai" (dimana bumi dipijak di situ ranting di patah, di situ air diambil, disitu langit di junjung dan di situ adat dipakai. Penerimaan terhadap pendatang (transmigran) dari pulau Jawa oleh masyarakat Minangkabau tersebut adalah dengan persyaratan bahwa mereka yang datang adalah pemeluk agama Islam karena masyarakat Minangkabau merupakan masyarakat yang adatnya berpatokan kepada Islam dan Alqur'an. Kemudian transmigran harus mampu menyesuaikan diri dan tunduk kepada adat-istiadat yang berlaku di tempat mereka ditempatkan. Tunduk kepada adat istiadat yang dimaksudkan disini adalah bahwa setiap pendatang yang ditempatkan di suatu tempat di ranah Minangkabau harus bersedia mengikuti adat dan ketentuan yang ada di tempat tersebut dengan pengertian bahwa mereka yang datang agar bisa dianggap kemenakan dalam hubungan adat Minangkabau. Kesediaan masyarakat transmigran untuk mengikuti adat yang berlaku agar bisa dianggap sebagai kemenakan di adat Minangkabau di tempat ia ditempatkan dalam bahasa Minangkabau disebut dengan "Malakok".

Secara etimologi, Malakok adalah istilah Indonesia khususnya Minangkabau, yang berarti menempel atau melekat rapat sekali. Kamardi Rais Dt. P. Simulie dalam (Eriyanti, 2009: 9) mengemukakan bahwa Malakok merupakan suatu cara penerimaan pendatang untuk masuk dan menjadi anggota suku Minangkabau. Eriyanti menyatakan bahwa istilah Malakok dalam bahasa Inggris sama dengan istilah yang dikemukakan oleh Emile Durkheim yaitu adhere, cementing social bonds yang mengandung tujuh unsur pokok sebagai berikut: 1) Menjadi pendatang dan bermukim di lingkungan salah satu suku Minangkabau, 2) Dengan kemauan sendiri, 3) Secara perorangan atau pun berkelompok, 4) Bertujuan untuk menjadi anggota suku, mendapat perlindungan dan keamanan, menjalin ikatan sosial yang kuat, mendapat perlakuan yang baik, dan adakalanya untuk mendapat hadiah tanah, 5) mengajukan permohonan dan bersumpah untuk taat setia dan menjaga kehormatan suku, 6) mengisi adat mengikuti persyaratan yang ditetapkan oleh penghulu suku, mengadakan 
perjamuan atau upacara kenduri untuk seluruh anggota suku.

Menurut menurut Kamardi Rais Dt. P. Simulie dalam (Eriyanti, 2009: 19) mengemukakan bahwa Malakok merupakan suatu cara penerimaan pendatang untuk masuk dan menjadi anggota suku Minangkabau. Cara penerimaan tersebut sesuai dengan ketentuan dan adat yang berlaku di Minangkabau yaitu dengan menjalani rangkaian upacara mengisi adat. Masyarakat luar etnik Minangkabau perlu pula mengembangkan pola pembaruan Malakok yakni pembaruan yang sering terjadi dalam lingkungan masyarakat Minangkabau dimana orang-orang yang dari luar etnik Minangkabau dapat diterima secara adat menjadi warga dan diakui sebagai bagian dari orang Minangkabau melalui suatu upacara adat.

Kegiatan tradisi Malakok yang terjadi dalam suatu daerah memiliki ciri khas sendiri dan prosesi upacara serta seserahan kepada adat ataupun kepada kaum yang akan menjadi suku ataupun kaum yang akan dilakokan. Kemudian yang Malakok akan menyediakan suatu seserahan wajib pokok kepada pemangku adat atau yang dituakan didaerah yang akan diberlangsungkan kegiatan Malakok.
Hafizah mengatakan (dalam jurnal penelitian tentang Malakok September 2017: 155) Makna Malakok adalah sangat besar terhadap pendatang baru dan masyarakat Minangkabau terutama jika:

a. Terjadi pernikahan pada keluarga tersebut. Ketika urang sumando yang datang dari luar, maka segala haknya dalam kehidupan bermasyarakat akan terlindungi. Warga pendatang juga tidak malu dengan keluarga calon besannya ketika baralek gadang karena si anak bersuku dan ada niniak mamak yang menanti kedatangan niniak mamak calon besan.

b. Dalam hubungan suami istri, jika terjadi perselisihan diantara mereka berdua yang dia tidak mampu untuk manyelesaikan, maka dia dapat mengadu kepada niniak mamak atau keluarga lain yang sesuku dengan mereka. Sehingga dapat menjadi penengah dan sekaligus memilah hak-haknya menurut aturan adat yang berlaku di nagari. Kusuik disalasaikan kok karuah di janiahkan, anyuik dipinteh. Artinya dia tidak perlu menjemput mamak atau keluarganya yang berada di luar Nagari Tambun Ijuak untuk manyelesaikan persoalannya itu. 
c. Jika terjadi permasalahan adat maka niniak mamak yang akan menyelesaikannya.

d. Warga pendatang yang Malakok lebih dihargai oleh masyarakat.

Leni Syafyahya (2006) menerangkan bahwa Malakok bertujuan dalam kelancaran suatu acara apabila melibatkan acara pernikahan masyarakat lokal dengan kaum pendatang. Acara Malakok anak dan acara Malakok sebagai masyarakat menetap biasa, maka Malakok adalah jalan yang sesuai untuk dilaksanakan di daerah. Pentingnya Malakok dalam mewujudkan keharmonisan hubungan telah diungkapkan oleh beberapa peneliti. Misalnya penelitian yang dilakukan oleh Eriyanti (2004), dkk. Sehubungan dengan itu, Abdullah (1978) dalam Eriyanti (2009) menegaskan bahwa Malakok merupakan local wisdom yang dapat membantu mewujudkan keharmonisan antara etnik pendatang dengan etnik tuan rumah maupun antara suku ataupun kaum di daerah Minangkabau. Realita yang ada di Tambun Ijuak menunjukkan bahwa program yang dibuat oleh Wali Nagari belum berjalan dan sulit mendapatkan biaya yang diperlukan oleh kaum pendatang serta waktu pelaksanaan proses Malakok yang memakan waktu.
Dalam tradisi Malakok yang ada di daerah kenagarian Tambun Ijuak, seseorang yang telah sah Malakok dengan suatu kaum ataupun suku di Tambun Ijuak akan mendapatkan alek adat atau penerimaan kehadiran adat dalam prosesi adat nigari. Jika suatu hal galok atau kematian yang terjadi pada nan Malakok maka disediakan tanah paujuang tabiang atau pandam pakuburan kaum. Syarat merupakan suatu tuntutan atau permintaan yang harus dipenuhi. Dengan kata lain, apabila tuntutan telah dipenuhi maka permintaan pun akan dikabulkan. Begitu pula dengan permintaan suku. Suku akan didapatkan apabila tuntutan adat telah dipenuhi sesuai dengan pepatah adat, "Cupak diisi limbago dituang " artinya ada aturan tersendiri untuk memenuhi suatu kewajiban pada keadaan yang berbeda-beda. (Leni Syafyahya, 2006: 2)

Suku-suku yang menjadi tempat Malakok di Kanagarian Tambun Ijuak sebanyak 5 suku. Suku yang dijadikan sebagai tampek Malakok yaitu suku Simabua Kutianyia, Chaniago, Koto, Piliang. Pemilihan suku yang dijadikan tempat Malakok didasarkan pada data dari keluarga dan perorangan yang Malakok di Tambun Ijuak dan didapatkan beberapa kesulitan maupun keluhan baik itu dari segi ekonomi 
atau biaya hingga prosesi yang sangat memakan waktu yang banyak.

Masalah sering muncul jika pendatang tidak melakukan Malakok maka mereka dilarang menikah dengan warga setempat karena dianggap orang yang tidak bersuku dan tidak berninik mamak serta tidak memiliki asal usul,. Kemudian warga pendatang tidak dihargai dan tidak dibawa rapat mufakat ketika mengadakan suatu acara Nagari. Warga pendatang merasa malu ketika ditanya oleh warga setempat tentang niniak mamak di Tambun Ijuak. Warga pendatang tidak bisa melakukan baralek gadang karena tidak ada niniak mamak yang akan menanti calon besan, tidak sedikit warga yang tidak Malakok merasa malu dengan calon besan ketika menikahkan anaknya yang tidak memiliki niniak mamak di Tambun Ijuak. Jika ada masalah adat seperti seorang anak dari keluarga pendatang yang melakukan hal perzinaan dengan suku lain maka niniak mamak tidak bisa menyelesaikan karena tidak Malakok. Masyarakat setempat pun sungkan untuk menolong warga pendatang jika belum Malakok karena rasa kekeluargaan itu tidak ada, sehingga menimbulkan kekecewaan pada warga pendatang. Jika terjadi perselisihan diantara suami istri yang mereka tidak mampu untuk menyelesaikan, maka mereka dapat mengadu kepada niniak mamak atau keluarga lain yang se-suku dengan mereka. Sehingga dapat menjadi penengah dan sekaligus memilah hak-haknya menurut aturan adat yang berlaku di Nagari. Masyarakat yang belum bisa melaksanakan Malakok merasa terasingkan karena hanya menetap begitu saja di Tambun Ijuak karena belum bisa melaksanakan Malakok. Jika ada acara di Tambun Ijuak mereka jarang mendapatkan undangan atau jamuan kepada keluarga yang tidak Malakok karena belum ada status yang jelas sebagai masyarakat yang sah.

Penulis dapat menjelaskan bahawa Malakok tersebut bisa sebagai syarat untuk pernikahan yang dilangsungkan oleh masyarakat luar daerah Minangkabau dengan masyarakat lokal daerah minangkabau terutama daerah kanagarian Tambun Ijuak. Proses Malakok ini dilaksanakan juga untuk orang yang membeli tanah, membuat rumah atau hanya mendiami daerah Kanagarian Tambun Ijuak dan proses Malakok.

\section{METODE PENELITIAN}

Jenis data yang akan digunakan dalam penelitian ini adalah data primer dan sekunder. Untuk memperoleh data maka diperlukan 
teknik/alat yang digunakan dalam penelitian. Teknik yang digunakan dalam penelitian ini adalah observasi, wawancara, dan studi dokumentasi. Teknik yang digunakan dalam keabsahan data adalah triangulasi. Dalam penelitian ini penulis melakukan uji keabsahan data yang bertujuan untuk melakukan check pada suatu penelitian yang sudah ditempuh. Teknik triangulasi adalah teknik pemeriksaan keabsahan data yang dimanfaatkan sesuatu yang lain dari luar data yang digunakan untuk keperluan pengecekan atau sebagai perbandingan terhadap data tersebut (Lexy J. Moleong, 2005:330). Teknik analisis data yang akan digunakan adalah teknik yang digunakan oleh Milles dan Huberman dalam Sugiyono (2010:337-345), menjelaskan bahwa aktivitas dalam menganalisis data kualitatif dilakukan secara interaktif dan dilakukan secara terus menerus sampai tuntas sehingga datanya sudah jelas. Aktivitas yang digunakan dalam penelitian kualitatif terdiri dari pengumpulan data, reduksi data, penyajian data, dan terakhir pemeriksaan kesimpulan atau verifikasi

\section{HASIL DAN PEMBAHASAN}

\section{Prosedur Tradisi Malakok}

$\begin{array}{rrr}\text { Amir } & \text { (2011: } & \text { 187-188) } \\ \text { menyatakan } & \text { bahwa } & \text { proses }\end{array}$

pembauran pendatang baru dalam struktur pasukuan asal maupun kesepakatan nagari membentuk suku baru bagi pendatang adalah dengan proses "Malakok" atau proses pembauran ala Minangkabau. Semua pendatang baru ini disebut kemenakan juga walaupun dengan hak yang berbeda dari kemenakan asli dari sukuan asal itu. Menurut Leni Syafyahya (2006: 2) syarat merupakan suatu tuntutan atau permintaan yang harus dipenuhi dengan kata lain, apabila tuntutan telah dipenuhi maka permintaan pun akan dikabulkan. Begitu pula dengan permintaan suku. Suku akan didapatkan apabila tuntutan adat telah dipenuhi sesuai dengan pepatah adat, "Cupak diisi limbago dituang " artinya ada aturan tersendiri untuk memenuhi suatu kewajiban pada keadaan yang berbeda-beda.

Dengan membandingkan teori dan kenyataan yang dapat di temukan di lapangan dapat dikatakan bahwa Malakok merupakan suatu tradisi daerah kanagarian Tambun Ijuak dapat memberikan ruang kepada pendatang baru yang berasal dari daerah luar Minangkabau dan mencari suku atau status yang dapat diakui didalam nagari atau daerah tersebut. Tradisi Malakok sangat penting dilaksanakan pada suatu kaum atau suku terutama 
pada kaum pendatang yang tidak bersuku di wilayah Tambun Ijuak, hingga masyarakat pedatang harus menempuh prosesi adat supaya diakui oleh satu nagari. Sementara untuk kaum pendatang harus mengikuti segala prosesi pokok yang harus dijalankan apa bila ingin diakui oleh suatu nagari dan dianggap sebagai masyarat yang bersuku dan mempunyai identitas adat di tengah masyarakat dan nagari.

Masyarakat yang berasal dari luar Minangkabau atau kaum pendatang apabila ingin melaksanakan prosedur Malakok di daerah yang dituju maka ada beberapa tahap yang harus di laksanakan oleh masyarakat pendatang maupun secara perorangan yaitu hal-hal yang perlu diketahui :

a. Penduduk yang keluar dan atau pindah ke daerah lain harus melapor kepada RT, RW, Kelurahan, Kecamatan dan Satuan Kerja Perangkat Daerah (SKPD) tempat bersangkutan berdomisili.

b. Penduduk yang pindah keluar dari daerah asal apabila tidak melapor kepada RT, RW, Kelurahan, Kecamatan dan Satuan Kerja Perangkat Daerah (SKPD) akan dikenakan Pembekuan Data Penduduk.

$\begin{array}{ccc} & \text { Tahap selanjutnya } & \text { yang } \\ \text { harus } & \text { dilaksanakan } & \text { oleh }\end{array}$

masyarakat pendatang yaitu jika pindah keluar antar Kab/Kota/Prov, dengan persyaratan berupa surat Pengantar RT, mengisi blanko pindah di Kelurahan, pasfoto dan KK serta KTP. Setelah semua persyaratan awal yang telah dilaksanakan oleh masyarakat pendatang di daearah asal maka tahap selanjutnya yang harus dilaksanakan yaitu melaksanakan tinjauan ke daerah yang dituju, melaksanakan petemuan awal dengan pimpinan daerah setempat atau wali nagari untuk melengkapi syarat-syarat yang harus di penuhi, menyiapkan berkas yang menjelaskan data diri ataupun perkelompok, melakukan penyerahan berkas data diri maupun kelompok kepada pemerintahan daerah setempat atau kantor wali nigari, mendengarkan arahan yang disampaikan oleh perangkat pemerintahan daerah terkait perihal yang dilaksanakan, memilih suku yang bisa dilakokan, menemui pihak keluarga yang ingin dilakokan beserta niniak mamak suku yang telah ditentukan, dan terakhir menunggu panggilan hasil kecakapan kelengkapan berkas yang telah diajukan.

Setelah persyaratan umum dilaksanakan dan telah memenuhi panggilan kecakapan berkas, maka 
persyaratan selanjutnya melaksanakan pertemuan dengan calon keluarga dan niniak mamak yang telah menerima pendatang tersebut untuk Malakok dan melaksanakan syarat Malakok selanjutnya. Adapun syarat atau tata cara Malakok di Minangkabau (Hafizah, 2017: 155) ialah:

a. Carano nan diisi jo siriah langkok, diateh carano dinan diisi jo siriah langkok batatakan ameh sabarek duo ameh. Bisa juga digantikan dengan uang yang senilai dengan harga dua emas yang seharga dengan emas yang berlaku disaat itu juga atu lebih sesuai dengan permintaan niniak mamak yang menyetujui.

b. Carano nan diisi langkok, diataeh carano diisi siriah langkok jo ameh jumlah gadang (5-8 ameh), dan tidak bisa digantikan dengan uang yang setara dengan jumlah emas yang diberikan tergantung permintaan penghulu, niniak mamak atau ketua adat.

c. Sekor kerbau atau seekor kambing akan dipotong dalam upacara pemberian suku dan untuk menjamu seluruh penduduk nagari.

Setelah syarat-syarat di atas dipenuhi, acara selanjutnya ialah permintaan persetujuan dari pihak suku yang akan menerima persetujuan (Zainal Arifin: 2011) tersebut dimulai dari: a. Pihak keluarga bapak yang akan menerima

b. Sanak saudara sekeliling

c. Semua kaum/kerabat yang sapasukuan dengan suku yang akan menerima

d. Jika tiga persetujuan di atas telah didapatkan, langkah selanjutnya ialah memberitahukan kepada wali nagari penduduk sekitar dan tetangga yang ada di lingkungan rumah yang Malakok untuk bisa memeriahkan dan ikut serta dalam kegiatan Malakok. Selanjutnya penandatanganan dokumen oleh pihak terkait diantaranya yaitu pihak keluarga yang dilakok-kan, sanak saudara sakaliliang, semua kaum peneria maupun pendatang, panghulu setiap suku.

Syarat dan prosedur pelaksanaan tradisi Malakok di Tambun Ijuak

Syarat dan prosedur pelaksanaan tradisi Malakok di Nagari Tambun Ijuak menurut ketua Kerapatan Adat Nagari Dt. Rajo Penghulu yaitu beragama islam, mempunyai suku di kaumnya, harus berpindah tempat kepada daerah yang baru ditempatinya, harus melaksanakan adat dengan istilah ditiggalkan mamak, didapati mamak, ditinggalkan kaum, didapati kaum, melaksanakan ketentuan sepanjang adat, melaksanakan Malakok 
tersebut dirumah bersangkutan. Jika sudah ada keluarga yang mau menerima baru diperjelas berupa emas yang harus keluarkan untuk kegiatan Malakok baik itu uang hidup atau uang mati, kemudian dipanggil orang yang berhak yang ada didekat rumah, niniak mamak, wali nagari, barulah yang bersangkutan mengadakakan pesta kecil. Hal-hal yang boleh dilaksanakan oleh orang Malakok yaitu boleh mengikuti rapat atau musyawarah nagari tapi tidak rapat adat, bisa ikut serta dalam acara nagari, orang yang Malakok tidak termasuk dalam ranji keluarga inti.

Setelah pelaksanaan syarat Malakok awal maka sebelum memasuki peroses selanjutnya ada beberapa kata pasambahan atau kata pembuka yang diucapkan diwaktu acara perhelatan pemberian suku. Pihak yang melakukan pasambahan ini ialah para penghulu setiap suku dengan penghulu suku yang akan memberikan suku terhadap anak tidak bersuku atau pihak yang mengadakan perhelatan. Tata urutan dari pasambahan tersebut ialah: yang membuka pasambahan ialah pihak yang meminta suku, dijawab oleh penghulu suku-suku lain di daerah tersebut, setelah itu pasambahan dilanjutkan dengan permintaan syarat oleh penghulu suku-suku lain di daerah itu jawaban dari pihak yang meminta suku - jawaban kembali oleh penghulu suku-suku lain - terakhir pasambahan ditutup oleh penghulu yang meminta suku.

Setelah proses perhelatan pemberian suku dilakukan kepada orang-orang yang tidak bersuku, maka yang bersangkutan telah diakui sebagai orang Minangkabau. Kaum pendatang ini akan menjadi kemenakan dalam suatu suku di Minangkabau. Namun memiliki hak yang berbeda dari kemenakan asli dari pesukuan asal itu. Kaum pendatang ini akan dipandang sebagai kemanakan dalam hubungan batali ameh. Kemenakan dalam hubungan batali ameh artinya hubungan yang terjadi antara pendatang baru berasal dari luar Minangkabau yang diterima dalam pesukuan Minangkabau dengan membayar semacam upeti. Kemenakan batali ameh ini tidak berhak menerima warisan gelar pusaka, tetapi mungkin dapat menerima harta warisan jika diwasiatkan kepadanya karena memandang jasajasanya/disebabkan uangnya (Toeh,1985:80).

\section{Dampak Tradisi Malakok}

Dampak Malakok ada yang positif dan negatif bagi kehidupan bermasyarakat. Dampak positif tradisi Malakok adalah berpindahnya satu keluarga atau satu kaum ke kaum yang lainnya 
dengan suku yang sama pada nagari yang ditempati. Istilahnya yaitu ditinggalkan kaum didapati kaum, ditinggalkan mamak didapati mamak, ditinggalkan induk di dapati induk, ditinggalkan bapak didapati bapak. Dari hasil wawancara dengan niniak mamak Ambrizal Janud Dt. Tandiko didapatkan jawaban sebagai berikut:

a. Apabila seseorang tidak melakukan tabang manumpu inggok mancakam atau Malakok, jika ada alek buruk atau kematian dan alek alek baik atau pesta perkawinan maka tidak akan ada orang yang datang. Kalau orang tersebut sudah Malakok maka seseorang tersebut sudah dianggap anak kemenakan nagari tempat orang tersebut Malakok. Jika ada kematian dan perkawinan akan dibantu oleh anak kemenakan dinagari tersebut.

b. Orang yang Malakok sangat diawasi oleh niniak mamak maka larangan di dalam Malakok salah satunya yaitu tidak boleh mencari menantu yang satu kaum atau yang kita tempati.

c. Setiap yang Malakok mendapatkan tanah pandam pakuburan yang merupakan hak dari yang Malakok tersebut. Larangannya mengenai sako jo pusako. Sako yaitu gelar penghulu sementara pusako adalah tanah kaum.

d. Tidak adanya rasa membebani serasa kita tinggal dikampung sendiri.

Di sisi lain terdapat juga dampak negatif yang ditimbulkan yaitu :

a. Malakok memerlukan upeti adat, artinya dalam meminta suku diperlukan biaya/materi. Bagi lelaki Minangkabau yang beistrikan perempuan di luar Minangkabau, memiliki kehidupan ekonomi yang miskin. Maka tidak dapat melaksanakan Malakok ini. Otomatis anak mereka tidak bersuku.

b. Ada masalah lain di samping upeti adat. Walaupun memiliki materi untuk membayar upeti adat, akan tetapi jika tidak ada suku/kaum yang mau menerima. Dengan demikian, kaum pendatang yang tidak bersuku juga tidak dapat diberikan suku.

c. Banyaknya prosedur yang dilaksanakan oleh kaum pendatang sangat menghabiskan waktu.

Malakok juga berperan penting dalam permasalahan yang dialami kaum atau seseorang yang bersangkutan apabila didalam lingkar Malakok yang telah dikisahkan sebelumnya. Menurut Eriyanti (2009) anggota masyarakat atau pendatang yang berasal dari luar adat nan salingka nagari atau 
dari luar Minangkabau yang dapat di lakok-kan atau dimasukkan kedalam suatu suku yang ada di nagari-nagari di Minangkabau. Seperti urang Samando, anak pusako, para pendatang baik sebagai pekerja buruh, berladang, pegawai atau pedagang yang tinggal dalam waktu lama di Minangkabau.

Dari temuan peneliti di lapangan keterlibatan Malakok didalam kehidupan masyarakat di Kanagarian Tambun Ijuak sangat berguna dan bermanfaat sekali. Karena sangat terealisasikan secara baik dan memberikan kemudahan terhadap masyarakat terutama masyarakat pendatang. Di lain sisi, masyarakat yang berada didalam nagari Tambun Ijuak sendiri sangat menerima jika ada yang Malakok kepada salah satu keluarga yang ada didalam nigari karena dapat menambah masyarakat baru dan bersilaturahmi dengan masyarakat pendatang.

Pandangan Masyarakat Terhadap Tradisi Malakok di Tambun Ijuak

Di Tambun Ijuak banyak terdapat orang yang melakukan tradisi Malakok. Masyarakat luar lebih dominan memilih tradisi Malakok yaitu untuk mendapatkan status atau atribut sebagai kaum serta mempererat hubungan kekerabatan serta menambah jumlah saudara. Dari hasil wawancara ditemukan bahwa tradisi Malakok ini bertujuan untuk mempererat tali silaturrahmi serta mencari keluarga baru. Dari orang yang melakukan proses Malakok ini mendapatkan keuntungan dalam mempermudah mengurus keperluannya di dalam masyarakat. Adapun faktor penyebab seseorang melakukan tradisi Malakok juga diungkapkan oleh Wali Nagari Tambun Ijuak bapak Hendra Dt. Bogah (dalam wawancara 10 Juni 2019) menyatakan bahwa orang Malakok di Tambun Ijuak mengambil status resmi sebagai masyarakat Tambun Ijuak. Urang Malakok tidak masuk ke dalam ranji yang pokok didalam keluarga yang di-lakok-an hanya mendapatkan mamak untuk tempat peraduan masalah dalam nagari.

Faktor pendorong seseorang melaksanakan tradisi Malakok diantaranya karena orang tersebut bukanlah orang Tambun Ijuak. Seseorang tersebut tidak memiliki sanak saudara. Untuk mencari kaum, apabila terjadi suatu permasalahan yang tidak diinginkan seperti perkelahian. Sebelum masalah tersebut sampai pihak kepolisian maka yang akan menyelesaikan masalah tersebut adalah mamak kaum yang diselesaikan secara adat, serta untuk mencari perlindungan ditempat tinggalnya. 
Implikasi Tradisi Malakok

Terhadap Masyarakat Lokal yaitu bisa menerima pendatang baru yang Malakok di daerah mereka. Kemudian tersedianya sarana pekerjaan baru bagi masyarakat lokal karena masyarakat pendatang membuka usaha dan pekerjaan lainnya yang menunjang kehidupan masyarakat lokal. Serta bertambahnya jumlah penduduk.

\section{SIMPULAN}

Dari uraian yang telah dijelaskan maka disimpulkan bahwa proses pra-pelaksanaan tradisi Malakok di Tambun Ijuak mempunyai beberapa prosedur yang dilaksanakan oleh kaum pendatang untuk bisa melaksanakan proses Malakok. Setelah pra-pelaksanaan tradisi Malakok, maka prosedur pelaksanaan tradisi Malakok dapat di laksanakan sesuai dengan syaratsyarat yang telah ditentukan. Sehingga setelah mendapatkan pencapaian dalam proses tersebut dapat dilakukan prosedur akhir Malakok tersebut. Jadi, prosedur tradisi Malakok memiliki implikasinya terhadap kehidupan masyarakat lokal dan kaum pendatang, sehingga menimbulkan dampak positif dan negatif terhadap masyarakat.

\section{DAFTAR PUSTAKA}

Lexy J. Moleong. 2009. Metode Penelitian Kualitatif.
Bandung: Remaja

Rosadakarya

Amir. 2011. Pola dan Tujuan Hidup

Orang Minang. Jakarta: Citra

Harta Prima

Sugiyono. 2012. Metode Penelitian

Kualitatif.Bandung: Alfa

Beta

Syafyahya, Leni dkk. 2006. Kata

Sapaan Bahasa

Minangkabau di Kabupaten

Agam

Eriyanti, Fitri. 2009. "Malakok:

Suatu Mekanisme Pendamai

Ala Minangkabau". Dalam

Jurnal Demokrasi Vol VI No

2 Tahun 2007.

Arifn Zainal. 2011. Adat

Kesepakatan Dan Politik

Adat Orang Minangkabau

Eriyanti Fitri. 2013. “Aspek Sosio-

Budaya : Kebijakan

Pemerintah, Dan Mentalitas

Yang Berpengaruh

Terhadap Integrasi Sosial

Dalam Masyarakat

Sumatera Barat". Dalam

Jurnal Integrasi dan Sosial

Masyarakat Voll XII No.1 Th.

2013.

Eriyanti, Fitri. 2016. "Malakok": Multikultural Consepts

Based On Local Wisdom In Minangkabau Community.

Hafizah, 2017. "Malakok Sebagai

Syarat Adat" Jurnal

Kepemimpinan Dan

Pengrusan Sekolah Vol.2 No.

2 Th. 2017 